\title{
THE
}

\section{Mobile Media: From Legato to Staccato, Isochronal Consumptionscapes}

\author{
Nikhilesh Dholakia \\ University of Rhode Island, transmod@uri.edu \\ Ian Reyes \\ University of Rhode Island, ianreyes@uri.edu \\ Jennifer Bonoff \\ University of Rhode Island
}

Follow this and additional works at: https://digitalcommons.uri.edu/com_facpubs
The University of Rhode Island Faculty have made this article openly available. Please let us know how Open Access to this research benefits you.

This is a pre-publication author manuscript of the final, published article.

Terms of Use

This article is made available under the terms and conditions applicable towards Open Access Policy Articles, as set forth in our Terms of Use.

\section{Citation/Publisher Attribution}

Dholakia, Nikhilesh, et al. "Mobile media: From legato to staccato, isochronal consumptionscapes."

Consumption Markets, \& Culture, vol. 18, no. 1, 2015, pp. 10-24. http://dx.doi.org/10.1080/

10253866.2014 .899216

Available at: http://dx.doi.org/10.1080/10253866.2014.899216 
"Mobile Media: From Legato to Staccato, Isochronal Consumptionscapes"

Nikhilesh Dholakia
College of Business Administration, University of Rhode Island

Ian Reyes

Department of Communication Studies, Harrington School of Communication and Media

Jennifer Bonoff

College of Business Administration, University of Rhode Island

This is a pre-publication manuscript of Dholakia, Nikhilesh, Ian Reyes, and Jennifer Bonoff. 2015. Mobile media: From legato to staccato, isochronal consumptionscapes. Consumption Markets, \& Culture 18 (1): 10-24. http://dx.doi.org/10.1080/10253866.2014.899216 


\section{$\underline{\text { Abstract }}$}

Mobile devices in the form of smartphones are transforming the temporality of consumption experiences, from languid and legato forms to isochronal and staccato forms. New communication technologies accelerate as well as alter mobile consumptionscapes. Rather than attempting to capture the elusive here-and-now essence of such fast-changing scenes, this essay invokes three historical episodes of technology and mobility - the transistor radio, the Walkman-style cassette device, and the MP3 player - to uncover the patterns that enhanced levels of mobility bring to the media consumption experience. In particular, by illuminating matters of time, some temporal framings are offered as correctives to spatially biased theories of mobile media. Drawing lessons from these historical episodes and blending in contemporary social theories about mobile technologies, we arrive at a temporally oriented view of the emergent consumptionscapes that can contribute to understanding the present era and the proximal future in terms of connecting both places and paces.

Keywords: mobile; media; consumptionscape; smartphone; radio; walkman; MP3 


\section{Introduction}

Too often, mobile media are construed primarily in terms of their spatial effects and implications (Innis 1951). To be sure, the widespread dispersal and connectivity of mobile devices across geo-spaces are the most immediately striking signs of a new media consumptionscape (Goggin 2011). Yet the underlying temporal domain of such widely dispersed connectivity is less obvious, less studied, and less well under stood as an equally definitive and impactful quality of the contemporary mobile consumptionscape. Examining temporality is a valuable adjunct to the spatially oriented accounts of new media and the "de-massification" of the mass market. Rather than thinking of mobility solely as a matter of moving through and possibly conquering space, in this essay we consider how mobile media also create temporal movements akin to the spatial fragmentation of the de-massed market. In a pragmatic sense, understanding temporality is essential for managing a market environment in which access and attention are measured in fractions of a second (see, for example, Warnaby 2013, for temporality in retail spaces).

Contemporary mobile markets are inextricable from so-called "smartphones" (Watkins, Hjorth, and Koskinen 2012) - devices that are essentially miniature, wireless, personal computers. Because smartphones are variedly convergent and rapidly evolving media, it is virtually impossible to offer a comprehensive analysis of such moving targets. Consumer music 
technologies, however, have a long history of mobility and convergence. Indeed, many of the technologies, industries, and markets for today's smartphones derive from previous technologies, industries, and markets for audio media (Dimmick, Feaster, and Hoplamazian 2011; Farnsworth and Austrin 2005; Goggin 2011; Watkins, Hjorth, and Koskinen 2012). In particular, technological entities related to music are often forerunners and heralds of socioeconomic and cultural changes in arenas of mobile technology (Attali 1985). Therefore, as we seek to refine an account of the temporalities defining the contemporary mobile consumptionscapes, we draw from scholarship on audio media and cultures to illuminate the matter (Askegaard 2010; Bradshaw and Shankar 2008).

Consumptionscapes are sites of connected consumption and shared culture (Ger and Belk 1996; Hahn 2004). Communication technologies do more than carry messages; they embody and shape human values and experiences in the lifeworld (Askegaard 2010; Moisander and Eriksson 2006). Thus, when the common paths connecting consumers change, new consumptionscapes emerge, and these historical-material changes have implications down to the roots of social experience: space and time. Our effort to articulate the temporal dimensions of mobile consumptionscapes is informed by the history of mobile audio. ${ }^{1}$ We review three key historicalmaterial configurations of audio mobility leading to the present age of smartphones. In each case, we observe how the mobilization of a medium affects the consumptionscape, thereby presenting new challenges and 
opportunities for those developing and marketing these devices and the content for them. The first case examines the mobilization of broadcast radio via transistor technology, the second case examines the mobilization of analog recordings through cassette technology, and the third case examines the mobilization of digital music via MP3 technology. Consequently, our goal is twofold: first, to establish a theoretical position on mobility that better accounts for time, not just space; and second, to raise critical questions about temporality in contemporary and emerging mobile consumptionscapes by mapping how time has been constructed and changed across three historicalmaterial configurations of mobile music media. Before tackling specific cases, however, we must first contextualize our concern for temporality vis$a^{`}$-vis media "mobility."

\section{Modes of Mobility}

Cochoy (2009) cautioned that consumer research usually dwells on subjectivist approaches to marketplace phenomena at the expense of historical and material research and, in so doing, misses the point on what is specific to mediation or the newness of that mediation:

Indeed, in order to solve the consumption enigma, this discipline [consumer research] thinks it has to go deeper and deeper into the consumer psyche, without realizing that this leads it to perpetually ignore the material entities which should yet be considered as part of the explanation. As a result, consumer research faces the risk of obscuring the mystery it pretends to illuminate ... $(32-33)$ 
Yet when pursuing a historical-material analysis of any new medium, the trouble is that media technologies and markets for them change so quickly as to challenge nearly any effort to develop broad categories, taxonomies, or theorizations (Graham, Zook, and Boulton 2012; Scolari, Aguado, and Feijo'o 2012).

For the study of mobile media, the essential problem is that there is no such thing as an immobile communications medium. Yet, each medium may be mobile in its own ways and, furthermore, it is the mode of mobility that separates one form from another, often with significant implications for society. Such is the lesson of comparing speech to writing, the difference between these two having been a touchstone for media theorists from Plato onward. Typical is Ong's (1982) account of the differences in social power, epistemology, and historical consciousness stemming from differences in the primary means of communication, oral, or written. Making communications more mobile in space and persistent through time, via writing, is one of the pillars of civilization as we know it. Ong (1982) even opines that Plato's capacity for abstraction, including his critique of writing-based society, was itself the product of having under gone that techno-social shift (24).

Poster (1990) argued, however, that understanding electronic media requires one to move beyond this basic dichotomy; the persistent trouble is that new media tend to be cast as just another form of writing, rather than as means by which space and time may be affected in a manner unlike writing. Similar to Plato and Ong, Poster contends that a society's primary "mode of 
information" is integral to networks of social and economic power, and that the defining characteristics of any mode of information are those affecting a society's experience of time and space. Yet while Poster's theory of the mode of information was forward thinking in some respects (e.g. on the role of databases), he glossed over core aspects of mobility by hyperbolizing rather than theorizing, arguing that:

... words cannot any longer be located in space and time, whether it be the "real time" of spoken utterance in a spatial context of presence or the abstract time of documents in a bureaucrat's file cabinet and library's archive. Speech is framed by space/time coordinates of dramatic action. Writing is framed by books and sheets of paper. Both are available to logics of representation. Electronic language, on the contrary, does not lend itself to being so framed. It is everywhere and nowhere, always and never. It is truly material/immaterial. (Poster 1990, 85)

Just as it now seems ludicrous to attribute to (comparatively) weak desktop computers and wired internet connections the potency of demolishing space and time, it would be terribly naive to hold that the current mode of mobility transcends spatio-temporal restrictions. Indeed, identifying the ways in which electronic "language" is "framed" by the social and material exigencies of media defining the current mode of mobility (e.g. smartphones) motivates much of the more recent research on new media.

The mode of mobility for today's electronic communications still relies on "moorings" to real, fixed locations as did industrial and broadcast era technologies (Hannam, Sheller, and Urry 2006). Still, what we now call "mobile" devices may be categorically distinct from merely "portable" 
technologies in that the former can maintain (wireless) connections to such moorings with less regard for place as compared to the latter (Campbell and Kwak 2010). New mobilities are also distinguishable by the (re)framing of public and private places, against which social power and mores are reshaped (Berry and Hamilton 2010; Farnsworth and Austrin 2005; Warner 2002). The social construction of public/private space can be further refined in the ways smartphones supplant place with "locatedness" (Ito, Matsuda, and Okabo 2005). The paradigm of mobility can also be expanded to include more than communications, extending also to the economic, environmental, and health impacts of the movement of people and products in addition to information (Hannam, Sheller, and Urry 2006). Nonetheless, though such accounts well theorize the social and technological contexts affecting new constructions of space, relatively little has been said about new temporalities. Among the few who focus on the temporality of the emergent mode of mobility are Hannam, Sheller, and Urry (2006) and Arnold (2003).

Hannam, Sheller, and Urry (2006) contend that

Not only does a mobilities perspective lead us to discard our usual notions of spatiality and scale, but it also undermines existing linear assumptions about temporality and timing, which often assume that actors are able to do only one thing at a time and that events follow each other in a linear order. (13)

The widespread availability of multiple communication channels for multiple media means that mobile users are spread not only across multiple, simultaneously inhabited spaces/places/locations, but also multiple media 
temporalities that tend to be repetitive, recursive, fragmented, or fleeting; rather than linear. In fact, Arnold (2003) presents the most cogent and provocative position regarding temporality and mobility:

... we live in a condition that concentrates time and diminishes space as a focal concern in our lifeworld, and the mobile phone is of great assistance in creating an organizational and social environment in which movement in space is routine, and the problematic is our movement and coordination in relation to time. (245)

For all the research focusing on mobility as a spatial phenomenon, is not the basic lesson that space is of diminishing relevance? Certainly, this is an epochal change, but for mobilities research - to whatever extent space has become less relevant to mobile users - time must gain in prominence within our research. The present and, likely, near future modes of mobility should see pace as an equal or greater concern than place.

Having identified the need to contend more deeply with temporality in the present mode of mobility, and having noted in the previous section that audio media, in particular, have been forerunners of mobile technology, culture, and markets, we move now to discuss three configurations of mobility found in the evolution of audio media. From these, we will glean three different pacings, or techno-social constructions of time, affecting and affected by these modes of mobility. Based on these, we hope to provide a more substantial theoretical and historical context for future research taking up the challenge to think beyond the spatial aspects of mobile media. 


\section{Three Historical-Material Configurations of Mobile Audio}

Mediation is essentially concerned with mobility because it entails moving information through connections between different points in space and time. All media, in that sense, are mobile, and therefore any critical work concerning today's "mobile media" requires clarification and contextualization. Indeed, the seeds of all "new" media always come from elements and tendencies observable in "old" media (Bolter and Grusin 2000). Paradigmatic cases in the history of audio media articulate a historical-material context for the contemporary "smart device-based" mobile markets, refine the concept of "mobility," and highlight enduring continuities as well as sharp disjunctures from the past. Overall, although the rhetoric of "mobility" implies that a changing market space is at the heart of the matter, we will show that temporality is the more appropriate axis by which to theorize the most definitive aspects of consumptionscapes evolving around contemporary "mobile" media.

\section{$\underline{\text { Transistors and Mobile Radio }}$}

The first instance to consider is the mobilization of radio consumers following the rise of transistors in the 1950s. Early twentieth century, radio technology generated electrical signals using fragile, expensive, and hot vacuum tubes powered by large, caustic batteries. While such systems were portable in principle, in practice these radios did not become commonplace and mobile technologies. Indeed, the mobilization of radios happened after 
the invention of transistors in the 1940s. Transistors, or semiconductors, are capable of generating electrical signals more efficiently, using less power and generating less heat. Transistors are also considerably smaller, cheaper, and sturdier than tubes. By the mid-1950s, portable transistor radios began to permeate public spaces, albeit as extensions of private lives. Maverick communication theorist McLuhan (1964), commenting on the post-1950s evolution of radio in America, observed:

With television accepting the central network burden ... radio was free to diversify and to begin a regional and local community ... radio can turn to individual needs of people at different times of the day ... [with the radio] now in pockets. Different programs are pro vided for different parts of the day. Once a form of group listening that emptied churches, radio has reverted to private and individual uses. The teenager withdraws from the TV group to his or her private radio. (144)

Radio is an opportune point through which to enter the history of mobile media for two reasons. First, the commercial model for broadcast radio laid the foundation for twentieth century electronic media. The broadcast commercial model endured through the twentieth century; however, the twenty-first century brought change. Contemporary digital networks require new commercial models that are quite unlike the mass-audience (broadcast) models of newspapers, network TV, and early radio. Second, the miniature, portable, and personal qualities of transistor radios make them akin in form and function to the contemporary miniature, portable, personal computers called "smart phones." Portable transistor radios altered not only how 
information moved but also the ways consumers are mobilized, thus altering social space and time, thereby defining a new consumptionscape.

Sterne's (2003) analysis of early twentieth century technical and promotional literature for radio found that "early graphic representations of sound reproduction show sound-reproduction technology to be embedded in networks that are simultaneously social and technical" (225). Commenting on a 1920s Radio Corporation of America diagram describing how radio broadcasting works, he notes how the technology was invented and promoted through imagining how different places - like the concert hall and the living room - would comingle, thanks to the mediating space of the broadcast station. This is more than an explanation of point-to-point communication; it is a vision of a new society for which space would take on new contours.

Time was also to undergo transformations in the radio age. Marinetti and Masnata’s (1992) "La Radia" manifesto predicted the possibility of receiving broadcast stations situated in various time zones and the lack of light will destroy the hours of the day and night. The reception and amplification of the light and the voices of the past with thermoionic valves will destroy time. (267) 
Although commercial broadcast radio in the USA would develop quite differently from the Italian futurists' vision, time was indeed altered, though hardly destroyed. Radio broadcast schedules were developed to fit with the flow of listeners' domestic lives, and domestic life came to revolve around radio broadcasts (Douglas 1999; Tacchi 2003). With the spread of transistor radios in the $1950 \mathrm{~s}$, radio began to affect public life as well.

Originally, in the earliest decades of the twentieth century, radio itself was the main product; the central attraction to radio was the experience of the technology itself. By the 1930s, however, radio listeners became more discriminating about radio content, and an industry was built to provide more desirable programming (Douglas 1999; Taylor 2005). Nevertheless, content in and of itself is worth little if it is not integrated into the lifeworlds of its intended audience. Douglas (1999) found that by the 1950s, when transistors made possible cheaper, smaller, more portable radios

... [m]odes of listening were increasingly tied not just to what you listened to but to where and how you listened - while falling asleep in your bed, making out on the beach, and especially driving around in the car. While listeners might have a favorite station, they also shopped around, often moving among three stations with different formats depending on their spirits, the time of day, and what they were doing. (221)

Similarly, Bull's analysis of car stereo listening finds that certain conditions of social space and time may be transformed by mobile audio:

These areas of everyday life [such as commuting], undertaken in public spaces, have often been assumed to be "unscripted" and void of interest. Automobile habitation rather sees inhabitants rewriting their daily scripts through the mediation 
of sound. The aural script of "driving time" is imposed upon those mundane and routine periods of empty time, thereby reclaiming and transforming them. Alternatively, the "script" is extended into linear time in order to delay involvement in the "bad" script of the unpleasurable and inevitable everyday. (Bull 2003, 370 - 371)

Mobile audio media have been used - indeed developed - for the purpose of enabling listeners to restructure time, or rewrite their scripts, so that "empty" time can be filled, or so that something scripted or inevitable may become more bearable.

In response to these social uses as well as the rise of television as the new, dominant medium for the latter half of the twentieth century, the radio industry restructured itself to become a more local and demographically segmented medium, creating and scheduling content with the interests of geographically targeted and demographically specific users in mind (Douglas 1999). Yet radio's rhythms emanated in real time from a central broadcaster, uniting many places in time and orienting them toward these centers of information. "Mobility," in this case, is about maintaining a more constant connection between senders and receivers. We will term this a "legato" temporality (Table 1).

Through the case of radio, we identify a relationship between the marketing of hardware with regard to form and content. That is, the mobile radio consumptionscape is informed partly by listeners' desires to engage the medium of radio as such, and partly by their desire to use its content to enhance or alter the temporal flow of everyday life. Radio technology as well 
as radio programming evolved to meet these desires. In each of the cases of mobile media examined here, this interplay between consuming the medium and consuming its content is paramount in structuring the temporality of each mobile consumptionscape. In this regard, commercial radio is the most archaic insofar as it operates on the old mass media paradigm; the product of commercial radio is not content, which is free, it is the attention of a target audience, "eardrums" that are sold to advertisers. This affects a legato temporality: a compositional palette of time and space-segmented audiences served smoothly to advertising pitch-makers (Table 1).

Table 1: Legato, Staccato and Isochronal Temporalities

\begin{tabular}{|l|l|l|}
\hline Temporality & Elaboration & Examples \\
\hline Legato & $\begin{array}{l}\text { Smooth, languid, shared, programmable, } \\
\text { centralizing, easily manageable }\end{array}$ & $\begin{array}{l}\text { Broadcasting: traditional } \\
\text { commercial radio (in USA) or } \\
\text { non-commercial music radio (in } \\
\text { Europe). }\end{array}$ \\
\hline Staccato & $\begin{array}{l}\text { Intermittent, individualistic, time-shifted, } \\
\text { burst-like, dispersive, often frenetic, } \\
\text { difficult to manage }\end{array}$ & $\begin{array}{l}\text { Recording: personal cassette } \\
\text { players, car stereos, "boom- } \\
\text { boxes", Also digital downloads } a \\
\text { la iPod }\end{array}$ \\
\hline Isochronal & $\begin{array}{l}\text { Intermittent, individualistic, time-shifted; } \\
\text { but also repetitive, recurrent, and cyclic; } \\
\text { somewhat more manageable than } \\
\text { staccato temporality }\end{array}$ & $\begin{array}{l}\text { Digital Networking: multi- } \\
\text { platform streaming services, a la } \\
\text { carte on-demand content } \\
\text { (Pandora, Spotify). }\end{array}$ \\
\hline
\end{tabular}

Commercial radio is glacial compared to newer media because of the time it takes to render an audience as a market through processes such as demographic research, audience measurement, and space - time-slots brokering. Furthermore, because they occur in real-time, radio broadcasts produce a temporally unified audience, experiencing the same content in the same time, a legato configuration, often over widely dispersed distances, thanks to station networking; indeed, people across the continental USA 
literally swaying together to a Four Tops tune on the networked Oldies station on their radio dials. And although the radio industry conceived new technologies, programming strategies, and networking schemes with an eye toward how mobile listeners sought to use the medium, very little power was in the hands of the audience. Of course, with newer mobile media interacting with streaming radio content, some changes have started to occur - but only at the margins, as of now, as we note later in this paper.

\section{$\underline{\text { Cassettes and Personal Stereos }}$}

The history of recording and record consumption runs in tandem with the history of broadcast radio, though it is part of a different configuration with its own temporality. Like the problems with vacuum tubes, record players spinning vinyl discs were ill suited for portability. Though tape technology existed in the $1930 \mathrm{~s}$ - and portable, suitcase-sized reel-to-reel recorders were manufactured - it is the smaller, self-contained cassette tape, combined with transistors that made possible the wearable tape players and portable boom boxes of the 1970s. Cassettes were invented in 1963 in order to facilitate dictation, but their ease of use and portability led to a major market shift, making it the dominant consumer audio format by the 1980s despite the fact that early cassettes offered lower quality sound than vinyl records (Braun 2002, $161-162)$.

Cassettes and "personal" (i.e. mobile) stereos, including boom boxes, car stereos, and portable cassette players, are worth examining because they 
were among the first to be studied as "new media." As Manuel (1993) found of old new media including photocopiers, cable television, fax, and cassettes:

Technologically, several of them involve similar features of miniaturization, transmission, display, and of storage and retrieval. More importantly, they constitute a challenge to the one-way, monopolistic, homogenizing tendencies of the "old" media (especially cinema, television, and radio). The new media tend to be decentralized in ownership, control, and consumption patterns; they offer greater potential for consumer input and interaction, and heighten the user's control over the form of consumption and over the relation to the media sender. Their emergence highlights the manner in which oppositional or affirmative tendencies or potential may lie less in the specific content of the media than in the means of production of that content. (2)

This remains the thrust of new media theory even in the digital age. Cassette technologies and culture offer an early point of comparison for understanding what "mobility" is, how it may be understood as a temporal phenomenon, and why it matters in the present day.

As with radio, the content of cassettes ultimately matters less than their mode of production, the technologies, and the institutions controlling them. Recapitulating McLuhan's (1994) dictum, “the medium is the message," cassettes and personal stereos, as Manuel (1993) described, affected social space (from centralized and unidirectional to decentralized and reciprocal). These also affected time.

The success of Sony's Walkman, for example, was due to the ways the company combined market research and product design (du Gay et al. 1997). Based on commercial research into mobile audio users, Sony 
identified two consumer paradigms, "escape" and "enhancement" (du Gay et al. 1997, 92). From the preceding discussion of radio, it should be clear that - in the media context - these paradigms derive from mobile radio culture. As Jenkins (2009) argues, new media technologies are developed and deployed within existing media cultures. The market for cassettes and personal stereos existed already in the audience for phonographs and radio. Yet compared to mobile radio, personal cassette players offered wholly new temporal experiences for mobile listeners. Although radio technology and programming were designed to meet listeners' desires for escaping and augmenting everyday life, broadcast technologies offered limited control of this experience, and cassettes allowed mobile listeners to overcome that limitation.

For one, cassettes freed mobile listeners from broadcast schedules, allowing them to program their own content, making them mobile in time as well as space. Choosing recorded over broadcast content is often referred to as "time-shifting" when it comes to television. In fact, such "time-shifting" has long occurred with audio media. While undoubtedly much of the content consumed on cassette was similar or identical to the content offered through radio, the difference was that it could be parsed and made available when the user wanted it. Of course, while this had long been possible in homes with phonographs, personal cassette players allowed people to take this power out of the house and on the go. In that sense, the advent of personal cassette players was a technological and cultural shift on par with mobile telephony: 
powers once available only privately were extended into public spaces and, in terms of temporality, made a particular kind of temporal experience itself more portable. "Mobility," in this case, is a matter of extending private control into public places by making more ubiquitous a formerly restricted temporal possibility; this yields a mode of mobility with a staccato temporality.

Yet, clearly, personal stereos did not ruin the radio industry. Radios as well as portable cassettes and their respective temporalities continued to appeal to consumers, and portable cassette devices, in many designs, combined radio and tape functions (i.e. they were convergent media) permitting users to alternate between the temporal mass-flows of broadcast and the individualized time-shifted flows of recorded music, between tuningin to content uniting listeners in a network's broadcast radius (legato temporality) or tuning-out for a more personalized experience (staccato or isochronal temporality). But in switching between radio and cassette listening, users also switch from being a product to being a consumer; personalization comes only with this price. Radio audiences are primarily a product (eardrums for "sale" to advertisers), and only secondarily become consumers when mobilized to purchase through advertising. Cassette listeners, on the other hand, are ab initio consumers - they buy the blank or prerecorded cassettes. There is less temporal divide between a cassette audience and a cassette consumer. 
Cassettes also facilitated the culture of piracy of electronic content still plaguing music markets in the digital age. The conglomerate structure of major media corporations, however, made piracy rather different in the cassette era. For example, a user could pirate music from a Sony artist on a Sony dual-cassette deck connected to Sony speakers with a Sony blank cassette later played on a Sony boom box. Contrasting the legato engagement with radio, where users are organized through a single medium to receive centrally programmed content in real time, resulting only secondarily in consumption, this is a more staccato temporality. In a staccato consumptionscape, there are multiple sites of interaction whereby consumption may happen in various ways, yet consumption is the sine qua non for the temporal experiences the medium was designed to offer. Time shifting via cassette was only possible for those possessing the content to be shifted. The degree of users' power to inhabit a "shifted temporality" is proportional to their ability to acquire content and the relevant delivery systems for that content; the more one consumes (of course, via higher levels of consumer spending), the more malleable time becomes. More to the point, the means of production for mobile cassette audio empower users and decentralize control of content, though this occurs through a countervailing demand to consume in order to realize this power. It is within and against this milieu - and its implied consumerist entrapment - that the unwillingness (or at least reluctance) of the post-1990 Millennial generation to purchase music, and other media content, gains significance. Cassette era music 
piracy, like today's, is not simply about acquiring free music, it is also about magnifying one's power to create and inhabit a different, more staccato temporality that is customized and individualized, and more difficult for marketers to manage. ${ }^{2}$

\section{From CD to MP3 to the cloud}

If controlling content is required to enhance one's temporal efficacy, then the drive to acquire as much content as possible at the lowest price is the logical extension of that condition. The Moving Picture Experts Group Audio Layer 3 (conventionally abbreviated as MP3) format made it possible to separate (to rip) more efficiently compact disc audio files from the discs themselves. Today, the "MP3" has become a generic term describing any kind of data-compressed audio format like Advanced Audio Coding, Windows Media Audio, or Ogg Vorbis. Though the most obvious effect of MP3 compression is data reduction (reducing a large audio file to a fraction of its original size) which permits more content to be stored in less space, the temporal impact of data compression is experienced more directly, therefore becoming more of a market consideration when digital networks are the conduits for consuming MP3s and other content.

The difference between analog and digital is that analog is coded as a single, continuous, physical signal; while digital signals consist of a series of discontinuous data samples. The process of digitization and the quality of that process rest on how many times per second a sound is sampled 
(sampling rate) and how much information is captured in each sample (bit rate). One of the temporal benefits of this for users is that they can move or copy digital audio files much faster than real time - in effect, adding time compression as another arrow (in addition to spatial mobility and timeshifting arrows) in the audio user's quiver. For most of the analog era, it was impossible to record or transmit audio signals faster than real time: it took 3 minutes for a 3-minute song to be recorded or transmitted. This issue was so important that cassette deck manufacturers eventually offered high-speed dubbing (a limited form of time compression), allowing duplication to happen somewhat faster than real (playing) time. But digital audio accelerated this process beyond what was possible with analog technology, and thus expedited many of the old practices of audio media users. But mere acceleration does not constitute a different temporality. Where these aspects of digital formats become more salient, more definitive of a new temporality is the situation when they intersect with digital networks.

The MP3 format made moving digital audio files through the internet much easier than moving CD quality digital audio. In that sense, the MP3 format was born of the need to make audio information more mobile. Sterne (2012) notes that MP3 liberated digital audio files from CDs, rendering the "ripped" songs and tracks more suitable to networked computing by tailoring them for the limited bandwidth and storage capacities of early internet-based digital media. Similar to cassettes, the early audio quality of this new format was a step backward from less mobile options like CDs. Yet again, 
consumers chose high portability over high definition. Although storage and bandwidth have greatly increased, the lower definition format remains the new standard.

One cultural reason for the popularity of this new format was that these digital files were easy for users to copy and transfer, yet difficult for regulators to monitor and regulate. Piracy remains rampant and the record industry is still reeling from this blow, struggling to find new ways to secure the old revenue stream. The market for recorded audio content and the drive to consume content in order to enhance temporal agency, legally or not, are part and parcel of the culture of portable audio rooted in the mid twentieth century's staccato consumptionscape. By Manuel's (1993) standards, MP3 tracks and portable MP3 players are considered new media because they challenge the power of old media systems, miniaturize the hardware and software (making them more portable), instantiate new transmission channels, and upset social and economic power relations. Yet many of these impacts have more to do with the market context in which MP3s are created and consumed; hence why it is necessary to consider the entire means of production, not just this new format.

MP3 on its own is not radically different from cassette or CD era technologies when it comes to questions of mobility. Rather, it is the combination of the MP3 format with wireless internet technologies, especially cellular phone networks, that spawns a new type of mobile market. A non-networked MP3 player is essentially just a personal 
stereo; there are still multiple, staccato, points of spatial/temporal interaction prior to listening to content on the player (ripping from $\mathrm{CD}$ or downloading from a server to put files on a computer before transferring them to the mobile player).

Bull (2003) looks specifically at the Apple iPod and posits that MP3 technology allows users "unprecedented power of control over their experience of time and space" (343). While earlier iterations of audio described in this paper - in particular cassette and CD technology - allowed for transportability, the advent of MP3 technology gave users the capability of storing thousands of songs in contrast to the limited storage capacity of the previous technology. As a result, aural needs are satisfied by the minute. A user can manage mood and orientation to space instantaneously:

The world beyond the music being played through the iPod becomes a function of the desire of the user and is maintained through time through the act of listening. The world is thus brought into line through acts of privatized, yet mediated, cognition. The users' sense of space is one in which the distinction between private mood or orientation and their surroundings is often abolished. The world becomes one with the experience of the iPod user. (Bull 2003, 351)

While the iPod can hold thousands of songs, streaming forms of audio technology encapsulated within services such as Pandora or Spotify allow for seemingly limitless choice, accessible in fractions of time that had to be spent in pre-digital forms. When cell phones and MP3 players converge, a new medium - hybridizing radio and recording temporalities - emerges. This new medium has a consolidated interface: the smartphone. To be sure, a full 
analysis of smartphones and music consumption would be beyond the scope of this paper; we will focus only on those aspects most related to the media genealogy established in the preceding sections. In particular, the advent of cross-platform streaming music services is noteworthy.

Smartphones are such astoundingly convergent technologies that "phone" seems a misnomer. It is nonetheless useful to understand why it may still be appropriate to think of these devices as "phones." This new technology still relies on old mobile phone infrastructures, both material and economic. Cellular phone networks are like radio networks, and likewise carry signals over radio frequencies (albeit in a different band). Yet the major spatial difference is that wireless phone signals can target individual mobile users and are therefore more spatially precise than radio. Temporally, the greatest difference stems from the fact that, for phone networks, the signal itself (airtime) is a commodity.

The quality and cost of a cellular connection are explicitly pegged to units of time (airtime) and to speed (e.g. 3G vs. 4G networks speeds of data transmission). The newness of this mobile technology is not that it connects different spaces, which is no different from earlier mobile media; it is the temporal relation between the spaces connected that matters most. Although digital technologies are often touted as offering "instant" communications, the fact is that problems of time (the fractional second delays and latencies) and of temporal efficiency (faster delivery, downloading, and sharing) remain at the core of digital networking. Faster transmission speeds are 
commodities in and of themselves, and the possibilities for mobile marketing hinge on capacities for cellular data transfer as well as on increasing user adoption of higher speed devices and connections. Whatever the purchase price of an MP3 file, even if it is free, the amount of data it contains determines the additional cost to download or stream it to a smartphone. The move to cloud storage and streaming (rather than recorded) media services ensures that mobile users will continue to pay for more cellular data. As digital technology and culture move from a personal storage paradigm to a cloud storage paradigm, and from marketing digital content to marketing permission to access content, this dimension of mobile temporality becomes increasingly important.

Streaming services combine the staccato allure of commanding vast media resources in making a commercial service out of the acquisition and management of those resources, re-centralizing power in a manner more like the broadcast age. Nonetheless, the palette being served up is not the languid, legato, swaying-together audience segments for the benefit of advertisers; rather, it is the frenetically evolving mega-pastiche of songs of all genres served up to the listener in the form of on-demand content and streams tailored for individual tastes: fragmental experience torrents that can flow across multiple hardware devices, from desktop computers to smartphones to game consoles to internet-equipped car stereos, and beyond.

The personalized radio stations and on-demand archives offered by today's music streaming services re-centralize power and thus extend and 
enhance some of the market logics of broadcast, especially audience/market surveillance. Radio's model of selling the attention of certain market segments to advertisers seems quaint compared to the data mining and trafficking of current new media services. One of the biggest differences between this and prior eras of mobility, from a marketing perspective, is that it is not a vague media activity of a mass of consumers (e.g. radio listeners, the blank cassette market, and MP3 pirates). Identities and behaviors of individual consumers can now be panoptically tracked, recorded, analyzed, and sold. These consumers inhabit a temporality that may switch between media streams that may be more legato (e.g. digital streams of broadcast radio) or more staccato (e.g. songs on-demand), but whatever the flow of experience, it is specific to the consumer and that specificity itself is a market object; these temporalities are isochronal. Instead of millions of swaying-together eardrums, the race is now on to sell each eardrum - for sale to content creators and advertisers - at a price that the person with that eardrum, or the advertiser seeking that eardrum, is willing to fork out.

The other deciding factor in this more isochronally temporal consumptionscape is the dwindling importance of hardware. Certainly, smartphones are the most visible component of this new mode of mobility, and the ability for users to enjoy previously immobile media functions anywhere in the radius of a wireless data connection is remarkable. But something arguably more radical is taking place with shifts to technologies like streaming media, social networks, and "the cloud." These services allow 
consumers to have the same, consistent, personalized, and monitored/monetized experience with little regard for which device is used. That is, whereas older mobile media were made "mobile" by virtue of miniaturization (e.g. transistors and MP3 data compression), this new mode of mobility witnesses something quite different: it is not the mobility of the media that matters as much as the mobility of consumers. Server-side technologies facilitating consumers' access (and access to consumers) regardless of the device enhance the constant connectivity defining radio's languid mode of mobility while recouping much of the control lost in previous staccato consumptionscapes.

"Mobility," in this case, is isochronal, concerning channels and content geared toward more efficient and personalized data transfer between content creators, service providers, and consumers. It is about maintaining a more constant and carefully monitored - even though variegated in format terms - connection between consumers and multiple points of access. In this isochronal consumptionscape, rather than focusing on how multiple media converge in singular new devices, one should focus instead on how various new media converge upon the point of individual consumers (and their data).

\section{$\underline{\text { Discussion }}$}

With regard to the temporality of today's mobile consumptionscape, it is often said that users are "always-on" and that communications are "instant." But our observations show that such qualities are not specific to 
the present consumptionscape. An audio history perspective aids in demystifying central aspects of mobility. Mobility and its temporalities are historically specific, socio-technical constructs. Arguably, transistor radios and personal stereos offered mobile, always-on experiences. The time it takes for a radio signal to travel across great distances and then be transduced (via electrically vibrated diaphragms of the radio speakers) into sound is negligible, even compared to digital communications of today. Likewise, cassettes offer instantaneity with a rudimentary type of on-demand content. Yet one difference between them is spatial (where is the consumer at, when being "on"?); connecting to what is on the airwaves is unlike connecting to what is on tape. The other difference, however, is temporal (what produces the sensation of constancy, or always-ness?); the 24/7 programming of a centralized broadcasting system is unlike the repeatable, self-contained time-structures of recordings. Therefore, there is one question that deserves further attention: how are claims and qualities such as "always" and "instant" constructed through markets and marketing?

In all the cases discussed here, the materiality of the medium's form and content are paramount for understanding the construction of space and time, and therefore the definition and experience of "mobility" in each consumptionscape. These observations are proffered pursuant to Cochoy's (2009) call to better illuminate the "mystery" of consumption by learning from material history rather than from consumer psychology. Taking up this task with regard to the mystery of mobility, we used historical facts about 
media technologies that originated in the twentieth century as well as cultural theorizations from the eras concerned. By examining three historical, material configurations of mobility in audio media, we identified three paradigms of mobility: more constant connection between senders and receivers; extending private spaces into the public spaces; and last, increasing efficiency and monitoring of data transfer across a decentralized network. Though each has obvious spatial dimensions, we identified significant temporal aspects of each. To follow through on our theorizations, one would need to inquire - how do changing constructions and perceptions of time correspond, or not, to similar changes in space?

Leaving aside the sleekness of contemporary mobile media devices compared to boom boxes and Walkmans, the main changes have been in terms of making the content sources and streams very diverse and frenetic (the move from legato to staccato forms), giving the consumer-user the illusion of vast power and control of this content palette evolving at a frenzied pace, in terms of "anything, anywhere, anytime" access. The media empires are searching - and always re-searching, in the fast-paced venture financed era of technological "innovation" - for ways to extract economic rents in terms of payments for time, speed, convenience, sleekness, and rapid-fire obsolescence of devices and formats.

\section{Concluding Observations}


From the material history presented herein, we refined the concept of mobility in terms of temporality. Each historical-material configuration was found to impact the mode of mobility of the consumptionscape, bringing with it new challenges and opportunities for defining, regulating, and exploiting mobile markets. To further pursue this line of critical inquiry, rather than leaning inward toward consumer attitudes but instead outward toward the history and materiality of new media, one should aim to understand differing modes of mobility and the spatio-temporal constructions particular to each mode. There is need to explore in greater depth ways in which consumers are positioned as historical, sensate subjects; with needs and desires specific to each positioning. As mobile technologies morph into new fantastical forms (Pogue 2012), the need for such material-historic anchoring becomes even more compelling.

\section{$\underline{\text { Notes }}$}

1. There are other, mostly parallel histories of mobile audio for other purposes, such as mobile technologies used by the military, by the transportation industry, by live audio engineers, and by the telecommunications industry. Of these, it is the last, telecommunications, which intersects most with the trajectory of mobile consumer audio entertainment. A fuller consideration of the cases considered in this paper should include also an account of mobile telecommunications related to smartphones - but this has not been undertaken to keep the paper reasonable in length.

2. The major commercial success in terms of selling (and getting users to pay for) content, in the growing era of staccato temporality, has been Apple's iTunes service. By fractionating content into songs and tracks priced at 99cents each, iTunes has re-motivated millions of users to subscribe to a 
centralized retail service - to purchase content legally rather than obtain it via piracy.

\section{$\underline{\text { References }}$}

Arnold, Michael. 2003. “On the Phenomenology of Technology: The 'Janus Faces' of Mobile Phones." Information and Organization 13 (4): 231 $-256$.

Askegaard, Søren. 2010. "Experience Economy in the Making:

Hedonism, Play and Coolhunting in Automotive Song Lyrics." Consumption Markets \& Culture 13 (4): $351-371$.

Attali, Jacques. 1985. Noise: The Political Economy of Music. Minneapolis: University of Minnesota Press.

Berry, Marsha, and Margaret Hamilton. 2010. "Changing Urban Spaces:

Mobile Phones on Trains.” Mobilities. 5 (1): $111-131$.

Bolter, Jay David, and Richard Grusin. 2000. Remediation:

Understanding New Media. Cambridge: MIT Press.

Bradshaw, Alan, and Avi Shankar. 2008. "The Production and Consumption of Music." Consumption Markets \& Culture 11 (4): $225-227$.

Braun, Hans-Joachim. 2002. Music and Technology in the Twentieth Century. Baltimore, MD: Johns Hopkins University Press.

Bull, Michael. 2003. "Soundscapes of the Car: A Critical Study of Audio Habitation." In The Auditory Culture Reader, edited by Michael Bull and Les Back, 357 - 380. New York: Berg. 
Campbell, Scott W., and Nojin Kwak. 2010. "Mobile Communication and

Civic Life: Linking Patterns of Use to Civic and Political

Engagement.” Journal of Communication 60 (3): 536 - 555.

Cochoy, Franck. 2009. "Driving a Shopping Cart from STS to Business, and the Other Way Round: On the Introduction of Shopping Carts in American Grocery Stores (1936 - 1959).” Organization 16 (1): 31 55.

Dimmick, John, John Christian Feaster, and Gregory J. Hoplamazian. 2011. "News in the Interstices: The Niches of Mobile Media in Space and Time.” New Media \& Society 13 (1): 1 - 17.

Douglas, Susan. 1999. Listening In: Radio and The American Imagination. New York: Times Books.

du Gay, Paul, Stuart Hall, Linda Janes, Hugh Mackay, and Keith Negus.

1997. Doing Cultural Studies: The Story of the Sony Walkman.

London: Sage.

Farnsworth, John, and Terry Austrin. 2005. "Assembling Portable Talk and Mobile Worlds: Sound Technologies and Mobile Social Networks." Convergence 11 (2): $14-22$.

Ger, Gu" liz, and Russell W. Belk. 1996. "I'd like to buy the World a Coke: Consumptionscapes of the 'Less Affluent World'." Journal of Consumer Policy 19 (3): 271 - 304.

Goggin, Gerard. 2011. Global Mobile Media. New York: Routledge. 
Graham, Mark, Matthew Zook, and Andrew Boulton. 2012. “Augmented Reality in Urban Places: Contested Content and the Duplicity of Code." Transactions of the Institute of British Geographers 38 (3): $464-479$.

Hahn, Hans Peter. 2004. "Global Goods and the Process of Appropriation." In Between Resistance and Expansion, edited by Peter Probst and Gerd Spittler, 211 - 230. Münster: Lit Verlag.

Hannam, Kevin, Mimi Sheller, and John Urry. 2006. "Editorial: Mobilities, Immobilities and Moorings.” Mobilities 1 (1): $1-22$.

Innis, Harold A. 1951. The Bias of Communication. Toronto: University of Toronto Press.

Ito, Mizuko, Misa Matsuda, and Daisuke Okabo. 2005. Personal, Portable, Pedestrian: Mobile Phones in Japanese Life. Cambridge: MIT Press. Jenkins, Henry. 2009. “What Happened Before YouTube?” In YouTube: Digital Video and Participatory Culture, edited by Jean Burgess and Joshua Green, 109 - 125. Malden, MA: Polity Press.

Manuel, Peter. 1993. Cassette Culture: Popular Music and Technology in North India. Chicago, IL: University of Chicago Press.

Marinetti, Filippo T., and Pino Masnata. 1992. "La Radia.” In Wireless Imagination, edited by Douglas Kahn and Gregory Whitehead, 265 268. Cambridge: MIT Press.

McLuhan, Marshall. 1964. "Radio: The Tribal Drum." AV Communication Review 12 (2): 133 - 145. 
McLuhan, Marshall. 1994. Understanding Media: The Extensions of Man.

Cambridge: MIT Press.

Moisander, Johanna, and Pa"ivi Eriksson. 2006. "Corporate Narratives of Information Society: Making up the Mobile Consumer Subject.” Consumption Markets \& Culture 9 (4): 257 - 275.

Ong, Walter J. 1982. Orality and Literacy: The Technologizing of the Word. New York: Routledge.

Pogue, David. 2012. "Google Glass and the Future of Technology." New York Times Technology Column - Pogue Blog, September 13. http://goo.gl/w85qq.

Poster, Mark. 1990. The Mode of Information: Poststructuralism and Social Context. Cambridge: Polity Press.

Scolari, Carlos A., Juan M. Aguado, and Claudio Feijo' o. 2012. "Mobile Media: Towards a Definition and Taxonomy of Contents and Applications." International Journal of Interactive Mobile Technologies 6 (2): $29-38$.

Sterne, Jonathan. 2003. The Audible Past: Cultural Origins of Sound Reproduction. Durham, NC: Duke University Press.

Sterne, Jonathan. 2012. MP3: The Meaning of a Format. Durham, NC: Duke University Press.

Tacchi, Jo. 2003. "Nostalgia and Radio Sound.” In The Auditory Cultures Reader, edited by Michael Bull and Les Back, 265 - 280. New York, NY: Berg. 
Taylor, Timothy. 2005. "Music and the Rise of Radio in Twenties America: Technological Imperialism, Socialization, and the Transformation of Intimacy." In Wired for Sound: Engineering and Technologies in Sonic Cultures, edited by Paul D. Green and Thomas Porcello, $245-$ 268. Middletown, CT: Wesleyan University Press.

Warnaby, Gary. 2013. "Synchronising Retail and Space: Using Urban Squares for Competitive Place Differentiation.” Consumption Markets \& Culture 16 (1): 25 - 44.

Warner, Michael. 2002. Publics and Counterpublics. Brooklyn, NY: Zone Books.

Watkins, Jerry, Larissa Hjorth, and Ilpo Koskinen. 2012. "Wising Up: Revising Mobile Media in an Age of Smartphones." Continuum: Journal of Media \& Cultural Studies 26 (5): 665 - 668. 